\title{
Exploration of Verbal Aggressiveness and Interpersonal Attraction through Social Network Analysis: Using University Physical Education Class as an Illustration
}

\author{
Alexandra Bekiari, Spyreta Spyropoulou \\ Faculty of Physical Education and Sports Science, University of Thessaly, Thessaly, Greece \\ Email:sandrab@pe.uth.gr
}

Received 24 May 2016; accepted 18 June 2016; published 21 June 2016

Copyright (C) 2016 by authors and Scientific Research Publishing Inc.

This work is licensed under the Creative Commons Attribution International License (CC BY). http://creativecommons.org/licenses/by/4.0/

(c) (i) Open Access

\begin{abstract}
Analyzing a network sample of 67 students and professors at university physical education class, the authors aim to detect informal structures (hierarchies of targeting of verbal aggressiveness and interpersonal attractiveness), to point out determinants of these structural properties, and to formulate a typology of verbal aggression targets and attractive persons. Complete network analysis was applied on the sample. Four network analysis centrality indicators were used: in-degree, Katz status, pagerank and authority. Non-network and network determinants of being target of verbal aggressiveness or attractive were discussed. Basic results of the study were that, at least in particular university milieu the verbal aggressiveness does not seem to depend on the education level of the parents. Male nodes seem to be quite susceptible to become a target of verbal aggressiveness and also to be physically attracted (especially, of course, by female nodes). The professor that the students appreciate proves to be a determinant of targeting students for verbal aggressiveness. The appreciation proved to be related with social and physical attractiveness while the task attractiveness seems to be significantly correlated with the friends number. As for the attractiveness, the following types were proposed: a) the "perfect image": the one who is socially and physically attractive tends also to be task attractive and b) the "handsome" is the socially attractive. Regarding verbal aggressiveness in combination with attractiveness, two types of target emerged: a) the "immune star", namely a person who exerts social, physical and task attractiveness, without being a target, and b) the "targeted star", who attracts being a target.
\end{abstract}

\section{Keywords}

Verbal Aggressiveness, Attractiveness, Network Analysis, Typology

How to cite this paper: Bekiari, A. and Spyropoulou, S. (2016) Exploration of Verbal Aggressiveness and Interpersonal Attraction through Social Network Analysis: Using University Physical Education Class as an Illustration. Open Journal of Social Sciences, 4, 145-155. http://dx.doi.org/10.4236/iss.2016.46016 


\section{Introduction}

\subsection{Verbal Aggressiveness}

Verbal aggressiveness is considered as an aggressive form of communication that results in destructive effects on interpersonal relationships [1]-[16].

Studies conducted in the academic domain showed that verbal aggressiveness is negatively related to perceptions of immediacy and interpersonal attraction [3] [17]-[20], students' affective learning [1] [21] [22], students' attendance and participation [23], student perceptions of the teacher and state learning [24] [25], students' motivation and satisfaction [2] [6] [9] [26]-[29].

The perceived verbal aggressiveness of the instructor appears also to restrict understanding and credibility, affecting simultaneously the students' motivation and willingness to communicate [30] [31] and influences negatively satisfaction, competence effort and intrinsic motivation of students in the classroom [2] [8] [15].

Moreover, it has been supported that verbal aggression induces antisocial fair play behaviors while prosocial fair play behaviors are restricted by the verbal aggressiveness of instructors [10]. [6], also, mentioned that instructors' verbal aggression has a negative effect on the students' satisfaction as well as on certain motivation factors such enjoyment and interest, effort/importance and competence.

The relationship between students and teachers in class goes bad, when teachers ridicule, mock, humiliate or threaten students [32]. According to the findings of [33] research a student's humiliation from the teacher is the most common aggressive behavior, which may pose a threat to the identity of students. It is of the utmost importance that students feel comfortable with classroom climate which enhances understanding, encouragement and acceptance [34].

Finally, according to [35], the verbally aggressive students are usually males, who have high possibilities of failure or perceive their instructors as verbally aggressive [31]. Not only the gender (male) of students, but also their young ages are two factors that affect verbal aggressiveness [36]. Research consistently shows that verbally aggressive university students can be less satisfied with their working teams, less cognitively and communicatively flexible, less involved, can be found with lower levels of self-confidence and increased jealousy towards the non-verbally aggressive students [31] [37]-[40].

Moreover, students with high levels of verbally aggressive behavior are more likely to perceive their instructor as ideologically biased [41]. Moreover, according to [42], students' verbal aggressiveness could be associated with negative motives and students can be less likely to use the proposals or information given by the instructors to feedback in contrast with the non-verbally aggressive ones. The motives that urge the verbally aggressive students in communicating with their teachers can mostly derive from their willingness for forgiveness and slanderous reasons [43].

\subsection{Interpersonal Attraction}

The school environment is considered as one of the most significant factors of communication where the pupils can be educated not only from the teaching procedure-typical education-but also by the interpersonal communication with their instructors - untypical education [15] [44]. According to [45] the communication between student and instructor can be considered as a form of mutual interaction which occurs through verbal and nonverbal messages. Interpersonal attraction refers to the tendency of estimation and positive feelings for someone else [46]. It is believed as a determining factor for the development and continuation of relations in social environments where interaction exists [47]. Interpersonal attraction consists of three dimensions, social, task and physical attraction [48]. The most frequent expressions of interpersonal attraction are physical/general attraction and eye contact [49].

The students' motives for education are probably enhanced when the teacher uses the following behaviors: smile, gesture, has a relaxed posture, uses a variety of vocal expressions and a monotone voice during teaching [50] [51] concluded that there were positive correlations among task and social attraction, emotional learning and instructor's teleconference evaluations based in open and distant learning courses. Moreover, it is claimed that university students are attracted by the professionalism, sociability and appearance of their teacher and this has resulted in greater willingness to communicate and establish friendly relations with the instructor and in deeper interest for the lesson [52]. Finally, students are found their instructors, that verbally attacked, as less attractive (in task, socially, appearance) [19] [20]. 
Interpersonal attraction can influence the teachers' ability to fairly judge according to moral values [53]. According to [54], there is evidence that better teacher-student's relationships promote lower levels of aggressiveness. Also, the warmth of the teacher and the quality of relationships with their students, have been associated with increased rejection of the students' aggressive behavior, as the perceptions of the school environment and the personal beliefs significantly affect aggressiveness [55].

\subsection{Social Network Analysis}

An increased interest in the investigation of interpersonal relationship through complete network analysis has been observed recently [56]. According to [57], every relationship is a bond of power. Consequently, it could be of vital importance to investigate the correlations among relations of power, verbal aggressiveness and interpersonal attraction. A research of a complete social network analysis concluded that aggressiveness was mostly expressed verbally or indirectly. It was not affected by gender, tribe or grade of school education. However, females were more likely to become victims of aggressive behavior compared with males. In addition, it has been supported that aggressiveness could be expanded through social networks, as children seem to imitate their peers' aggressive behavior [58].

In recent research conducted by [3] a complete social network analysis was applied using algorithms (such as in-degree, Katz status, pagerank, authority). It has been found that gender and the parental level of education are negatively correlated with the development of verbal aggressiveness. Persons who ignore the public opinion and the intimacy in friendship, express verbal aggressive behavior. On the other hand, young appearance, imposing and eccentric appearance characteristics could protect against verbal aggressiveness. Big corporal size and dark skin color of female students seem to receive insulting comments.

Another survey concerning complete social network analysis has revealed that gender can be an important factor of intimacy, as better intimacy is developed among male students for pleasant communication purposes. What is also implied is that students of younger ages tend to be more physically attractive. Finally, the results have shown than attraction can lead to verbal aggressiveness [17]. Moreover, through network indicators can be identified indications of the nature and cause of verbal aggressiveness. It was found that the incremental aggressive behavior expressed by the difference between the received and outgoing actions and can be considered as behavior expressing idiosyncrasy. While proportional verbally aggressive behavior based on the ration of outgoing to the received actions expressing adaptability. As the basis of empirical data network used samples from schools prison inmates [4].

The aim of the survey was to depict structures of verbal aggressiveness and interpersonal attractiveness hierarchies and to examine the factors affecting the position in these hierarchies, using a sample of university students and professors at Physical Education Faculty as an illustration.

\section{Method}

The following network analysis indicators have been used, which are calculated by Visone software in normalized form (\%). Their structural meaning is the following (no formulas are presented, as they are easily accessible in the web).

1) In-degree (occasional hierarchy position). It is an elementary indicator of centrality. It is defined as percentage of diagonal interactions received by a certain node. It can be interpreted as an occasional property given by the first-contacted nodes.

2) Status suggested by Katz [59] (accumulative hierarchy position). Status is here calculated as a power series. It calculates chains of successive relations. It can be interpreted as a situation much deeper than indegree. However, it does not show how many the links are through which a node may achieve an immediate impact.

3) Pagerank (distributive hierarchy position). It is based on the transferred value (e.g. being insulted or attracted) from one node to others. It is quite similar to Katz status. However, it reveal more subtle layers of nodes and, thereby, it drastically restricts outliers. Furthermore, it prevents calculative deformations induced by Katz status.

4) Authority (qualified competitiveness). This indicates nodes attracting most links from many other nodes, who intensively seek to maintain links. Namely, high authority characterizes a student who has attracted links of many other students who intensively (not occasionally) are looking for something specific. 


\subsection{Sample}

A network is by definition a non-random sample. However, this is not considered to be a weakness, as purpose of this research was not the descriptive statistic (generalization of any descriptive quantitative property) but the analytical statistics (correlations).

Network ("snowball”) sampling has been conducted in a class of 62 students ( $4^{\text {th }}$ semester) and 5 professors from a Physical Education Faculty in October 2015. The sample consisted of 39 male and 28 female, aged from 20 to $65(M=23, S D=2.35)$. The participants belonged to different socio-economic status.

All students and professors were familiar with each other and have answered a standardized questionnaire about several forms of relation developed among them. The questionnaires should be named, because otherwise a complete network analysis would technically infeasible. It was emphasized to them that their names would be known only to the researcher. In this way, sincere information was expected to be received.

\subsection{Questionnaire}

The questionnaire consisted of two parts: a) non-network variables (e.g. gender, birth year etc.), and b) network variables (verbal aggressiveness and attractiveness). The part $b$ of the questionnaire was based on the Verbal Aggressiveness Scale [60] in order to measure verbal aggressiveness. Preliminary examination [60] supported the psychometric properties of the instrument. In particular, confirmatory factor analysis indicated satisfactory fit indices (CFI: 0.97, SRMR: 0.02), and internal consistency of the scale $(\alpha=0.96)$. The scale consisted of eight items (e.g., "insults students," "makes negative judgments of ability").

The part b of the questionnaire was based on the Interpersonal Attraction Scale [20] in order to measure interpersonal attraction. Preliminary examination [20] supported the psychometric properties of the instrument. In particular, confirmatory factor analysis indicated satisfactory fit indices $(\mathrm{CFI}=0.974$, RMSEA $=0.049$ ), and internal consistency of the scale (Cronbach's alpha: from 0.87 to 0.94 ). The scale consisted of fourteen items for task attraction (e.g., "I would be based on his help in order to complete a homework"), twelve items for social attraction (e.g., "he is friendly to me") and twelve items for physical attraction (e.g., "he has a nice appearance").

Finally, in part b, additional questions were added to the questionnaires of [60] and [20], about trust (advising about study issues, particularly humanities and natural Sciences), incentives (offering help), socialization patterns (companion within and outside faculty) and study and general cooperation. Examples of such questions were: "Whom you would like to ask about humanity issues?", "whose companion you desire to have outside the faculty?" etc.

\subsection{Statistical Analysis}

Visone 1.1 was used in order to process the network data for extracting the values of in-degree, Katz status, pagerank and authority for every node. Both non-network and network variables (in-degree etc.) were entered in SPSS 21. After normality control with Kolmogorov-Smorinov and Shapiro-Wilk, bivariate correlation Spearman was applied at significance level of $p \leq 0.05\left(^{* *}\right)$ and $p \leq 0.01\left({ }^{*}\right)$. Moreover, Spearman test was preferred to a multivariate analysis, not only because it is non-parametric and more appropriate for this data setting, but also because it is bivariate and, thus, offers a clearer overview of all possible correlations among variables (multivariate analysis would be more appropriate for examining fewer and more specific variables). Principal component analysis was also used for formulating typology. The interpretation of the results has been based on in-depth interviews. These were conducted with students in form of individual discussions as well as in form of focus groups for rapid introduction into the situation.

Additionally, it should be clarified that, on the one hand, it is well known that permutation techniques have been developed in order to deal with dependence limitations of network data (QAP, ERGM etc.). On the other hand, such permutation techniques concern probabilities of ties appearance and correlations between networks which are considered as "dependent" and "independent" variables as a whole. This is not the case in this research, where various centrality values of nodes (not ties) were correlated between each other as well as with non-network variables. The above-mentioned permutation techniques cannot not enable such a correlation. Apart from that, aim of this analysis is not to predict whether a network will come about from another but rather to estimate whether e.g. an occasional (high indegree) verbal aggressor tends to become an accumulative (high 
Katz status) physical aggressor. This can (and should) be calculated only with techniques of conventional analytic statistics such as Spearman. Moreover, this conventional approach has already been tested and used in multidisciplinary academic literature and seems also to be in accordance with empirical data of the reality [61]-[63].

\section{Results and Discussion}

\subsection{Examples of Structures}

In Figure 1, the circle form as well as several structures (hierarchies of Katz, pagerank and authority) of verbal aggressiveness and interpersonal attraction are presented.

Differences can be observed in density between these networks. The networks of attraction are denser than these of verbal aggressiveness. This is expectable, as the main aim of the students at the university is to cooperate in science and to be socialized and not to develop conflicts.
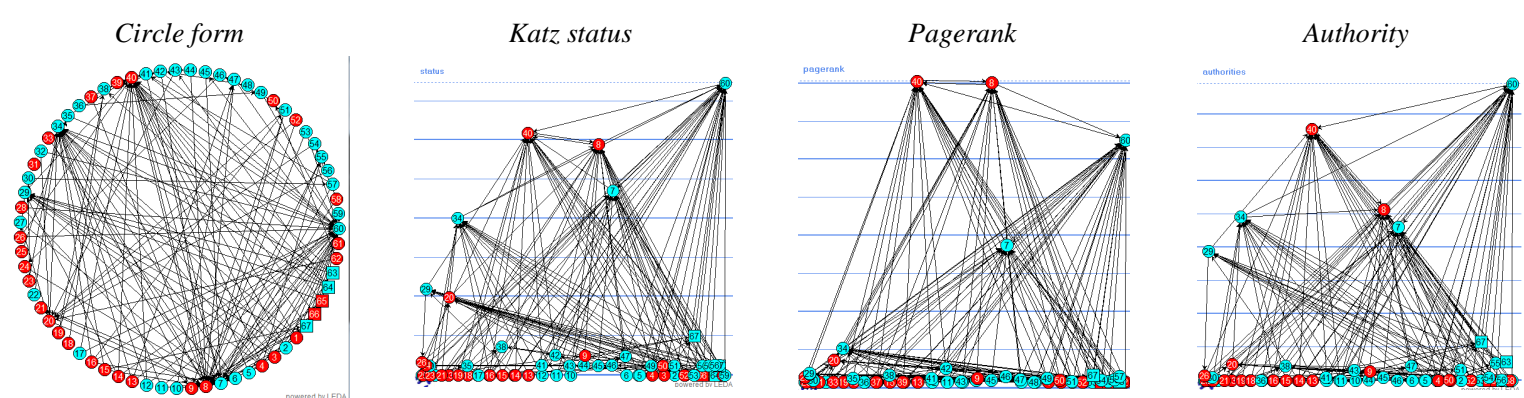

Relation: Verbal aggressiveness (offense), Nodes $=67$, links $=153$, density $=153 /(67 \times 67-67)=3.46 \%$
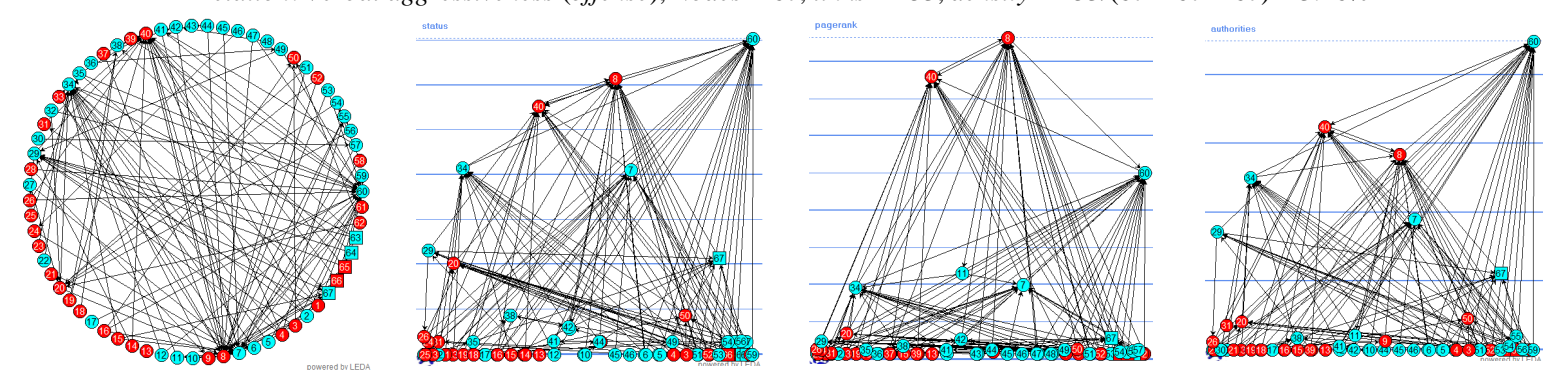

Relation: Verbal aggressiveness (irony), Nodes $=67$, links $=128$, density $=128 /(67 \times 67-67)=2.89 \%$
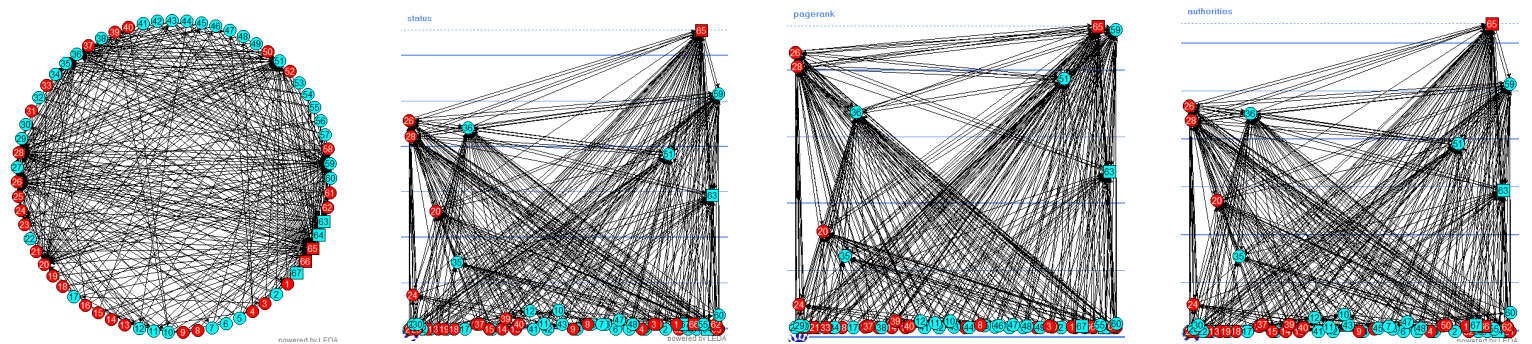

Relation: Task attraction (trust in research), Nodes $=67$, links $=360$, density $=360 /(67 \times 67-67)=8.14 \%$
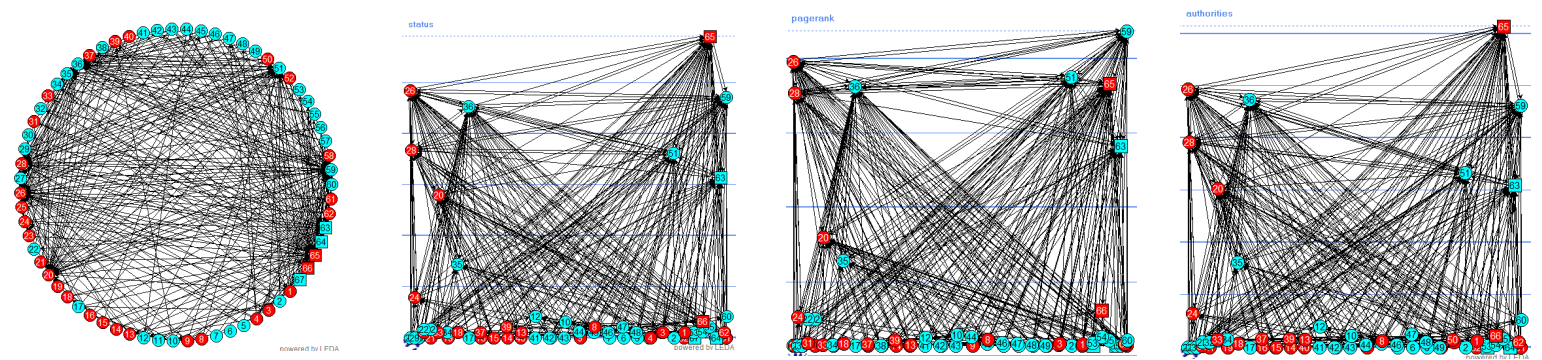

Relation: Social attraction (friendliness), Nodes $=67$, links $=340$, density $=340 /(67 \times 67-67)=7.68 \%$

Figure 1. Examples of structures in verbal aggressiveness and interpersonal attraction. 
Regarding hierarchical forms, professors are not at the top of verbal aggressiveness but rather on the top of some attraction hierarchies. The top nodes are in part the same and in part different ones in different hierarchies. For this reason, it is useful to apply several indicators (Katz, pagerank etc.) and not only one. Different indicators reveal different properties and meanings [56].

\subsection{Targeting for Verbal Aggressiveness and Attraction in Students and Professors}

It is firstly emphasized that parents' educational level are not included in Table 1, as they proved to be insignificant for attractiveness or verbal aggressiveness. Gender seems also to be of importance, as male nodes seem to be quite susceptible to become a target of verbal aggressiveness and also to be physically attracted (especially, of course, by female nodes). Experiences of travelling abroad do not play a significant role, while their perception of appreciation among each other is related to social and physical attractiveness. Although there is possibly self-knowledge and interpersonal intelligence, students are not interested in others appreciation. How big company group (friends) one supposes to have is related to task attraction. Finally, the number of instructors' appreciated seems to be influenced by the targeting of verbal aggressiveness. These results are in accordance with previous findings of [3] [64] [65], as the effect of the non-network parameters on the network structures are verified. Birth year as well as gender proves once again to play a significant role in the network structure.

\subsection{Target Typology}

In Table 2, the pure types of attraction and university students are examined. Task attraction is significantly correlated with the physical attraction and social attraction. If for example a university student seems to be socially and physically attractive, is regarded as a good scientist as well. Moreover, the "handsome" tends to be socially attractive too. Two types of attraction are proposed: 1) "perfect image" (namely the one who is socially and physically attractive tends also to be task attractive) and 2) the "handsome" (meaning the socially attractive person).

Table 1. Parameters of students’ interpersonal attraction and verbal aggressiveness.

\begin{tabular}{|c|c|c|c|c|}
\hline & Verbal aggressiveness & Task attraction & Social attraction & Physical attraction \\
\hline \multirow[t]{2}{*}{ Birth year } & 0.131 & $-0.336\left(^{* *}\right)$ & -0.210 & $-0.313\left(^{*}\right)$ \\
\hline & 0.321 & 0.009 & 0.111 & 0.016 \\
\hline \multirow[t]{2}{*}{ Gender $($ male $=0$, female $=1$ ) } & $-0.335\left(^{*}\right)$ & -0.226 & -0.264 & $-0.346\left(\left(^{*}\right)\right.$ \\
\hline & 0.018 & 0.107 & 0.058 & 0.014 \\
\hline \multirow[t]{2}{*}{ Distance from city center } & -0.006 & $0.598\left(^{*}\right)$ & -0.178 & -0.205 \\
\hline & 0.984 & 0.019 & 0.525 & 0.464 \\
\hline \multirow[t]{2}{*}{ Accommodation in flat } & 0.035 & $0.460\left({ }^{* *}\right)$ & 0.258 & 0.340 \\
\hline & 0.848 & 0.008 & 0.154 & 0.057 \\
\hline \multirow[t]{2}{*}{ Desired occupation with sport } & 0.223 & $0.454\left(^{*}\right)$ & 0.366 & 0.207 \\
\hline & 0.319 & 0.034 & 0.094 & 0.356 \\
\hline \multirow[t]{2}{*}{ Perceived acceptance of other students } & 0.076 & 0.269 & $0.343\left(^{*}\right)$ & $0.318\left(^{*}\right)$ \\
\hline & 0.594 & 0.056 & 0.014 & 0.023 \\
\hline \multirow[t]{2}{*}{ Interested in being accepted by other students } & 0.056 & -0.003 & -0.124 & -0.078 \\
\hline & 0.656 & 0.983 & 0.322 & 0.532 \\
\hline \multirow[t]{2}{*}{ Company group } & 0.039 & $0.282\left({ }^{*}\right)$ & 0.099 & 0.230 \\
\hline & 0.753 & 0.021 & 0.425 & 0.062 \\
\hline \multirow[t]{2}{*}{ Number of estimated students } & $0.295\left(^{*}\right)$ & 0.063 & -0.026 & 0.019 \\
\hline & 0.020 & 0.624 & 0.840 & 0.886 \\
\hline
\end{tabular}

${ }^{*}$ Correlation is significant at the 0.05 level (2-tailed). ${ }^{* *}$ Correlation is significant at the 0.01 level (2-tailed). 
In Table 3, two mixed types appear in targeting for verbal aggressiveness and attractiveness. The "immune star" who attracts everyone scientifically, physically and socially, without being targeted by anyone. Also, the "targeted star" who attracts everyone and, simultaneously, is a victim of targeting. It is noticeable that either the one or the other type seems to appear intensity, meaning the two edges, someone could be "immune star" or "targeted star". This means, either a "star" attracting strong admiration and, thereby, does not become a victim of targeting or a "star" creating envy and, thus, receives aggressiveness. Someone who is not a "star" is normally ignored by others.

These typology results seem to be complementary to the previous findings of [17] who have also proposed a connection of intimacy and attractiveness measured as a structural phenomenon. Thus, these properties which seem to be feelings prove to be also measurable as network variables. Moreover, they seem to be enhancing each other as well as interdependent with verbal aggressiveness [4] [58].

Network analysis is not included in general in many papers until now. However, this method is appropriate for detecting indiscernible structures and not for producing descriptive statistics. This strength and limitation should always be considered in such analyses.

Table 2. Typology of interpersonal attraction.

\begin{tabular}{ccc}
\hline & Social attraction & Physical attraction \\
\hline Task attraction & $0.656\left(^{* *}\right)$ & $0.529\left(^{* *}\right)$ \\
Social attraction & 0.000 & 0.000 \\
& & $0.622\left({ }^{* *}\right)$ \\
& & 0.000 \\
\hline
\end{tabular}

${ }^{* *}$ Correlation is significant at the 0.01 level (2-tailed).

Table 3. Students' typology of verbal aggressiveness and attractiveness.

\begin{tabular}{ccc}
\hline & & Type \\
\hline & 1 & 2 \\
\hline Friently behavior & $\mathbf{0 . 7 3 6}$ & $\mathbf{0 . 6 7 0}$ \\
Desire for friendly chat & $\mathbf{0 . 7 3 6}$ & $\mathbf{0 . 6 7 3}$ \\
Attractive appearance & $\mathbf{0 . 7 3 9}$ & $\mathbf{0 . 6 6 3}$ \\
Generally attractive appearance & $\mathbf{0 . 7 3 9}$ & $\mathbf{0 . 6 6 1}$ \\
Substantial assistance in scientific work & $\mathbf{0 . 7 3 7}$ & $\mathbf{0 . 6 7 2}$ \\
Valuable contribution to scientific work & $\mathbf{0 . 7 3 6}$ & $\mathbf{0 . 6 7 4}$ \\
Offensive behavior & -0.730 & $\mathbf{0 . 6 7 9}$ \\
Negative comments & -0.740 & $\mathbf{0 . 6 6 6}$ \\
Ironic comments & -0.735 & $\mathbf{0 . 6 6 4}$ \\
Rude behavior & -0.719 & $\mathbf{0 . 6 8 5}$ \\
Underestimated attitude & -0.711 & $\mathbf{0 . 6 9 4}$ \\
Causing bad feelings & -0.731 & $\mathbf{0 . 6 6 9}$ \\
Mocking behavior & -0.734 & $\mathbf{0 . 6 7 3}$ \\
Underestimation of intelligence & -0.730 & $\mathbf{0 . 6 7 6}$ \\
Verbal aggressiveness & -0.733 & $\mathbf{0 . 6 8 0}$ \\
Task attraction & $\mathbf{0 . 7 3 7}$ & $\mathbf{0 . 6 7 3}$ \\
Social attraction & $\mathbf{0 . 7 3 6}$ & $\mathbf{0 . 6 7 2}$ \\
Physical attraction & $\mathbf{0 . 7 3 9}$ & $\mathbf{0 . 6 6 2}$ \\
\hline Ex & &
\end{tabular}

Extraction method: principal component analysis; a 2 components extracted. 


\section{Conclusions}

Results of present study, regarding structures in verbal aggressiveness and interpersonal attraction, indicated that it is useful to apply several indicators (Katz, pagerank etc.) and not only one. Different indicators reveal different properties and meanings.

Basic results of the study were that, at least in particular university milieu the verbal aggressiveness does not seem to depend on the education level of the parents. Gender seems also to be of importance, as male nodes seem to be quite susceptible to become a target of verbal aggressiveness and also to be physically attracted (especially, of course, by female nodes). The professor that the students appreciate proves to be a determinant of targeting students for verbal aggressiveness. The appreciation proved to be related with social and physical attractiveness while the task attractiveness seems to be significantly correlated with the friends number.

As for the attractiveness, the following types were proposed: a) the "perfect image": the one who is socially and physically attractive tends also to be task attractive and b) the "beautiful" is the socially attractive. Regarding verbal aggressiveness, two types of target emerged: a) the "immune star", namely a person who exerts social, physical and task attractiveness, without being a target, and b) the "targeted star", who attracts being a target.

\section{References}

[1] Bekiari, A. (2012) Perceptions of Instructors' Verbal Aggressiveness and Physical Education Students' Affective Learning. Perceptual and Motor Skills, 115, 325-335. http://dx.doi.org/10.2466/06.11.16.PMS.115.4.325-335

[2] Bekiari, A. (2014) Verbal Aggressiveness and Leadership Style of Sport Instructors and Their Relationship with Athletes’ Intrinsic Motivation. Creative Education, 5, 114-121. http://dx.doi.org/10.4236/ce.2014.52018

[3] Bekiari, A. and Hasanagas, N. (2015) Verbal Aggressiveness Exploration through Complete Social Network Analysis: Using Physical Education Students' Class as an Illustration. International Journal of Social Science Studies, 3, 30-49. http://dx.doi.org/10.11114/ijsss.v3i3.729

[4] Bekiari, A. and Hasanagas, N. (2016) Suggesting Indicators of Superficiality and Purity in Verbal Aggressiveness. An Application in Adult Education Class Networks of Prisoners. Open Journal of Social Sciences, 4, 279-292. http://dx.doi.org/10.4236/jss.2016.43035

[5] Bekiari, A., Kokaridas, D. and Sakellariou, K. (2005) Verbal Aggressiveness of Physical Education Teachers and Students’ Self-Reports of Behavior. Psychological Reports, 96, 493-498. http://dx.doi.org/10.2466/pr0.96.2.493-498

[6] Bekiari, A., Kokaridas, D. and Sakellariou, K. (2006) Associations of Students' Self-Report of Their Teacher's Verbal Aggression, Intrinsic Motivation, and Perceptions of Reasons for Discipline in Greek Physical Education Classes. Psychological Reports, 98, 451-461. http://dx.doi.org/10.2466/pr0.98.2.451-461

[7] Bekiari, A., Patsiaouras, A., Kokaridas, D. and Sakellariou, K. (2006) The Relationship between Verbal Aggressiveness and State Anxiety in Volleyball. Perceptual and Motor Skills, 99, 630-634.

[8] Bekiari, A., Perkos, S. and Gerodimos, V. (2015) Verbal Aggression in Basketball: Perceived Coach Use and Athlete Intrinsic and Extrinsic Motivation. Journal of Physical Education and Sport, 15, 96-102.

[9] Bekiari, A. and Syrmpas, I. (2015) The Influence of Motivational Climate and Coaches’ Verbal Aggression on Athletes’ Satisfaction. British Journal of Education, Society \& Behavioural Science, 9, 318-329. http://dx.doi.org/10.9734/BJESBS/2015/17757

[10] Hassandra, M., Bekiari, A. and Sakellariou, K. (2007) Physical Education Teacher's Verbal Aggression and Student’s Fair Play Behaviors. The Physical Educator, 64, 94-101.

[11] Johnson, A.J., Becker, J.A., Wigley, S., Haigh, M.M. and Craig, E.A. (2007) Reported Argumentativeness and Verbal Aggressiveness Levels: The Influence of Type of Argument. Communication Studies, 58, 189-205. http://dx.doi.org/10.1080/10510970701341154

[12] Infante, D.A. and Rancer, A.S. (1996) Argumentativeness and Verbal Aggressiveness: A Review of Recent Theory and Research. Communication Yearbook, 19, 319-352.

[13] Infante, D.A. and Wigley, C.J. (1986) Verbal Aggressiveness: An Interpersonal Model and Measure. Communications Monographs, 53, 61-69. http://dx.doi.org/10.1080/03637758609376126

[14] Manoli, P. and Bekiari, A. (2015) EFL Teachers' Verbal Aggressiveness and Students' Intrinsic Motivation and Social-Affective Strategy Use: Investigating Possible Relations. Advances in Research, 5, 1-13. http://dx.doi.org/10.9734/AIR/2015/19692

[15] Myers, S.A., Edwards, C., Wahl, S.T. and Martin, M.M. (2007) The Relationship between Perceived Instructor Aggressive Communication and College Student Involvement. Communication Education, 56, 495-508. http://dx.doi.org/10.1080/03634520701466398 
[16] Rancer, A.S. and Avtgis, T.A. (2014) Argumentative and Aggressive Communication: Theory, Research, and Application. 2nd Edition, Peter Lang, New York.

[17] Hasanagas, N. and Bekiari, A. (2015) Depicting Determinants and Effects of Intimacy and Verbal Aggressiveness Target through Social Network Analysis. Sociology Mind, 5, 162-175. http://dx.doi.org/10.4236/sm.2015.53015

[18] Martin, M.M., Heizel, A.D. and Valencic, K.M. (1999) Verbal Aggression in Computer-Mediated Decision-Making. The Annual Meeting of the National Communication Association, Chicago, 12-15 November 1999, 21 p.

[19] Rocca, K.A. and McCroskey, J.C. (1999) The Interrelationship of Student Ratings of Instructors' Immediacy, Verbal Aggressiveness, Homophily, and Interpersonal Attraction. Communication Education, 48, 308-316. http://dx.doi.org/10.1080/03634529909379181

[20] Syrmpas, I. and Bekiari, A. (2015) The Relationship between Perceived Physical Education Teacher’s Verbal Aggressiveness and Argumentativeness with Students’ Interpersonal Attraction. Inquiries in Sport \& Physical Education, 13, 21-32.

[21] Myers, S.A. and Knox, R.L. (1999) Verbal Aggression in the College Classroom: Perceived Instructor Use and Student Affective Learning. Communication Quarterly, 47, 33-45. http://dx.doi.org/10.1080/01463379909370122

[22] Wrench, J.S. and Richmond, V.P. (2004) Understanding the Psychometric Properties of The Humor Assessment Instrument through an Analysis of the Relationships between Teacher Humor Assessment and Instructional Communication Variables in the College Classroom. Communication Research Reports, 21, 92-103. http://dx.doi.org/10.1080/08824090409359971

[23] Rocca, K.A. (2004) College Student Attendance: Impact of Instructor Immediacy and Verbal Aggression: Brief Report. Communication Education, 53, 185-195. http://dx.doi.org/10.1080/03634520410001682447

[24] Bekiari, A. and Sakellariou, K. (2002) Perceived Instructor Verbal Aggressiveness and Student State Learning in Physical Education. Italian Journal of Sport Sciences, 1, 251-256.

[25] Martin, M.M., Weber, K. and Burant, P.A. (1997) Students’ Perceptions of a Teacher's Use of Slang and Verbal Aggressiveness in a Lecture: An Experiment. The Annual Meeting of the Eastern Communication Association, Baltimore, 10-13 April 1997.

[26] Gorham, J. and Christophel, D.M. (1992) Students' Perceptions of Teacher Behaviors as Motivating and Demotivating Factors in College Classes. Communication Quarterly, 40, 239-252. http://dx.doi.org/10.1080/01463379209369839

[27] Mazer, J.P. and Stowe, S.A. (2015) Can Teacher Immediacy Reduce the Impact of Verbal Aggressiveness? Examining Effects on Student Outcomes and Perceptions of Teacher Credibility. Western Journal of Communication, 80, 21-37. http://dx.doi.org/10.1080/10570314.2014.943421

[28] Myers, S.A. and Knox, R.L. (2000) Perceived Instructor Argumentativeness and Verbal Aggressiveness and Student Outcomes. Communication Research Reports, 17, 299-309. http://dx.doi.org/10.1080/08824090009388777

[29] Myers, S.A. and Rocca, K.A. (2001) Perceived Instructor Argumentativeness and Verbal Aggressiveness in the College Classroom: Effects on Student Perceptions of Climate, Apprehension, and State Motivation. Western Journal of Communication (Includes Communication Reports), 65, 113-137. http://dx.doi.org/10.1080/10570310109374696

[30] Edwards, C. and Myers, S.A. (2007) Perceived Instructor Credibility as a Function of Instructor Aggressive Communication. Communication Research Reports, 24, 47-53. http://dx.doi.org/10.1080/08824090601128141

[31] Schrodt, P. (2003) Students’ Appraisals of Instructors as a Function of Students' Perceptions of Instructors’ Aggressive Communication. Communication Education, 52, 106-121. http://dx.doi.org/10.1080/03634520302468

[32] Docan-Morgan, S. (2011) “They Don't Know What It’s Like to Be in My Shoes”: Topic Avoidance about Race in Transracially Adoptive Families. Journal of Social and Personal Relationships, 28, 336-355. http://dx.doi.org/10.1177/0265407510382177

[33] Vallade, J.I. and Myers, S.A. (2014) Student Forgiveness in the College Classroom: Perceived Instructor Misbehaviors as Relational Transgressions. Communication Quarterly, 62, 342-356. http://dx.doi.org/10.1080/01463373.2014.911767

[34] Forward, G.L., Czech, K. and Lee, C.M. (2011) Assessing Gibb’s Supportive and Defensive Communication Climate: An Examination of Measurement and Construct Validity. Communication Research Reports, 28, 1-15. http://dx.doi.org/10.1080/08824096.2011.541360

[35] Kinney, T.A., Smith, B.A. and Donzella, B. (2001) The Influence of Sex, Gender, Self-Discrepancies, and Self-Awareness on Anger and Verbal Aggressiveness among US College Students. The Journal of Social Psychology, 141, 245275. http://dx.doi.org/10.1080/00224540109600550

[36] Onukwufor, J.N. (2013) Physical and Verbal Aggression among Adolescent Secondary School Students in Rivers State of Nigeria. British Journal of Education, 1, 62-73.

[37] Anderson, C.M. and Martin, M.M. (1999) The Relationship of Argumentativeness and Verbal Aggressiveness to Co- 
hesion, Consensus, and Satisfaction in Small Groups. Communication Reports, 12, 21-31. http://dx.doi.org/10.1080/08934219909367705

[38] Martin, M.M. and Anderson, C.M. (1996) Argumentativeness and Verbal Aggressiveness. Journal of Social Behavior and Personality, 11, 547-554.

[39] Martin, M.M., Anderson, C.M. and Thweatt, K.S. (1998) Aggressive Communication Traits and Their Relationships with the Cognitive Flexibility Scale and the Communication Flexibility Scale. Journal of Social Behavior and Personality, 13, 531-540.

[40] Wigman, S.A., Graham-Kevan, N. and Archer, J. (2008) Investigating Sub-Groups of Harassers: The Roles of Attachment, Dependency, Jealousy and Aggression. Journal of Family Violence, 23, 557-568. http://dx.doi.org/10.1007/s10896-008-9171-x

[41] Linvill, D.L. and Mazer, J.P. (2013) The Role of Student Aggressive Communication Traits in the Perception of Instructor Ideological Bias in the Classroom. Communication Education, 62, 48-60. http://dx.doi.org/10.1080/03634523.2012.721889

[42] Edwards, C. and Myers, S.A. (2010) The Relationship between Students' Self-Reported Aggressive Communication and Motives to Communicate with Their Instructors. Psychological Reports, 106, 131-133. http://dx.doi.org/10.2466/PR0.106.1.131-133

[43] Mansson, D.H., Myers, S.A. and Martin, M.M. (2011) Students’ Aggressive Communication Traits and Their Motives for Communicating with Their Instructors. College Student Journal, 45, 401-406.

[44] Sorensen, G.A. and Christophel, D.M. (1992) The Communication Perspective. Power in the Classroom: Communication, Control, and Concern, 35-46.

[45] Mottet, T.P., Martin, M.M. and Myers, S.A. (2004) Relationships among Perceived Instructor Verbal Approach and Avoidance Relational Strategies and Students' Motives for Communicating with Their Instructors. Communication Education, 53. http://dx.doi.org/10.1080/0363452032000135814

[46] Berscheid, E. and Walster, E.H. (1978) Interpersonal Attraction. Addison-Wesley, Reading.

[47] Unal-Colak, F. and Kobak-Uzun, K. (2011). Determining Interpersonal Attraction in Educational Environment and the Relation with Motivation. International Journal on New Trends in Education and Their Implications, 2, 47-56.

[48] McCroskey, J.C. and McCain, T.A. (1974) The Measurement of Interpersonal Attraction. Speech Monographs, 41, 261-266. http://dx.doi.org/10.1080/03637757409375845

[49] Bevan, J.L., Galvan, J., Villasenor, J. and Henkin, J. (2016) "You’ve Been on My Mind Ever Since”: Content Analysis of Expressions of Interpersonal Attraction in Craigslist. Org'S Missed Connections Posts. Computers in Human Behavior, 54, 18-24. http://dx.doi.org/10.1016/j.chb.2015.07.050

[50] Hsu, L. (2010) The Impact of Perceived Teachers' Nonverbal Immediacy on Students’ Motivation for Learning English. Asian EFL Journal-Special Issue, 12, 188-204.

[51] Aydin, S. (2012) A Review of Research on Facebook as an Educational Environment. Educational Technology Research and Development, 60, 1093-1106. http://dx.doi.org/10.1007/s11423-012-9260-7

[52] Weiss, S.D. and Houser, M.L. (2007) Student Communication Motives and Interpersonal Attraction toward Instructor. Communication Research Reports, 24, 215-224. http://dx.doi.org/10.1080/08824090701439091

[53] Nwankwo, B.E. (2013) Role of Gender, Emotional Empathy, Interpersonal Attraction on Moral Judgement. Life Psychologia, 21, 264-276.

[54] Henry, D.B., Farrell, A.D., Schoeny, M.E., Tolan, P.H. and Dymnicki, A.B. (2011) Influence of School-Level Variables on Aggression and Associated Attitudes of Middle School Students. Journal of School Psychology, 49, 481-503. http://dx.doi.org/10.1016/j.jsp.2011.04.007

[55] Elsaesser, C., Gorman-Smith, D. and Henry, D. (2013) The Role of the School Environment in Relational Aggression and Victimization. Journal of Youth and Adolescence, 42, 235-249. http://dx.doi.org/10.1007/s10964-012-9839-7

[56] Bekiari, A. and Hasanagas, N. (2015) Sociological Insights in the Education System: “Unlocking” Thepower Relations. Christodoulidis, Thessaloniki.

[57] Popitz, H. (1992) Phänomene der Macht. 2. Stark erweiterte Auflage. Tübingen.

[58] Faris, R. and Felmlee, D. (2011) Status Struggles Network Centrality and Gender Segregation in Same- and CrossGender Aggression. American Sociological Review, 76, 48-73. http://dx.doi.org/10.1177/0003122410396196

[59] Katz, L. (1953) A New Status Index Derived from Sociometric Analysis. Psychometrika, 18, 39-43. http://dx.doi.org/10.1007/BF02289026

[60] Bekiari, A. and Digelidis, N. (2015) Measuring Verbal Aggressiveness in Sport and Education. International Journal of Physical Education, 4, 12-21. 
[61] Hasanagas, N. (2011) Network Analysis Functionality in Environmental Policy: Combining Abstract Software Engineering with Field Empiricism. International Journal of Computers, Communications and Control, 6, 622-634. http://dx.doi.org/10.15837/ijccc.2011.4.2090

[62] Hasanagas, N. (2014) Managing Information in Forest Policy Networks: Distinguishing Influential Actors form the "Postmen”. Forest Policy and Economics (Forthcoming).

[63] Papadopoulou, E., Hasanagas, N. and Harvey, D. (2011) Analysis of Rural Development Policy Networks in Greece: Is Leader Really Different? Land Use Policy, 28, 663-673. http://dx.doi.org/10.1016/j.landusepol.2010.11.005

[64] Bekiari, A., Hasanagas, N., Theoharis, D., Kefalas, I. and Vasilou, A. (2015) The Role of Mathematical Object and the Educational Environment to Students’ Interpersonal Relationships: An Application of Full Social Network Analysis. 32th Congress Greek Mathematical Society, Kastoria, 28 October 2015-1 November 2015, 799-812.

[65] Bekiari, A. and Hasanagas, N. (2016) "Educating” in Physical Education, Theoretical Approaches and Practical Inquiries. Christodoulidis, Thessaloniki.

\section{Submit or recommend next manuscript to SCIRP and we will provide best service for you:}

Accepting pre-submission inquiries through Email, Facebook, Linkedin, Twitter, etc A wide selection of journals (inclusive of 9 subjects, more than 200 journals)

Providing a 24-hour high-quality service

User-friendly online submission system

Fair and swift peer-review system

Efficient typesetting and proofreading procedure

Display of the result of downloads and visits, as well as the number of cited articles

Maximum dissemination of your research work

Submit your manuscript at: http://papersubmission.scirp.org/ 